\title{
Staged Procedures after Failing Ring Fixators of Lower Limb? Series of 15 Cases Abstract
}

Bahaa Aly Kornah ${ }^{1}$, Hesham Mohamed Safwat ${ }^{2}$, Abdel-Aleem M Sultan ${ }^{3}$ and Mohamed Aly Abdel-AAl ${ }^{3 *}$

${ }^{1}$ Orthopedic, Al Azhar University Cairo Egypt, 90 D Ahmed Orabi Street, Mohandessin, Giza, Egypt

${ }^{2}$ Orthopaedic surgery, Al-Hussain University Hospital, Orthopedic Department, Al Azhar University Cairo, Egypt

${ }^{3}$ Othopedic Surgery, Elbakry, General Hospital, Ministry of Health, Cairo, Egypt

\begin{abstract}
Background: Failure of the fixators is a challenging, especially in the presence of osteoporosis, bone defect, pin track infection and joint stiffness. This study aims at evaluating the functional outcomes of the lower limb proposed two-stage management of non-union after failed ring external fixation.

Patients and Methods: 15 patients (six females) with age range 22-65 years enrolled in this study. Four had femoral fractures and eleven with tibial fractures. All were due to high-energy trauma and all were open ones ( 3 grade (I), 8 grade (II) and 4 grade (III)). Categorised AO classification, 5 type (A), 4 type (B) and 6 type (C). They initially treated by ring external fixators and had radiological signs of non-union. Treatment involved removal of external fixators, pin track and blood tests until no active infection. Non-union managed by refreshing the fracture ends, opening the medullary canal, packing the non-union with autogenous bone grafts then realigning the fracture properly and stabilizing it with locked plate or interlocking nail.
\end{abstract}

Results: Average duration of nonunion 9.8 months. Average delay prior to osteosynthesis after removal of external fixation 15 days. All non-unions healed on an average 5.2 months. According to the Karlstrom-Olerud scores, final functional outcome score was excellent 7 cases, good 5 cases, accepted 2 cases and poor one case.

Conclusions: Two-stage treatment of non-union of long bone after ring fixation is an effective tool and may be a favorable option with low risk of complications and a high level of functional outcomes.

Keywords: Open fractures; Ring fixation; Non-union; Locked compression plate

\section{Introduction}

Ring external fixators become popular in dealing with a lot of limbs problems. By fast growing of field of limb lengthening and reconstruction, they are considered powerful tools motivating surgeons to find solutions for many difficult musculoskeletal problems [1]. One of most common indications is fractures due to high injury trauma which is commonly comminuted and open ones. The incidence of non-union following such injuries varies in different studies of $5 \%$ to $20.3 \%$ [2-4]. The non-union is always atrophic type according to Weber-Cech classification [5]. Managing these cases relies on type of non-union, age of patient, general condition, surrounding soft tissue and neurovascular status of the limb. The protocol for the treatment is two-stage management; first removal of the fixator and eradication of infection if any. The second stage includes stabilization of fracture and bone grafting to stimulate bone healing and halting non-union [6-8]. The of the current work aims at assessing the final functional outcomes of the proposed two-stage management of non-union after failed ring external fixation.

\section{Patients and Methods}

Between 2008 and 2013, fifteen patients (nine males) with ununited lower limb long bones fractures after failed ring external fixation were enrolled in this study. The mean follow-up 39 months (range 2452 months). Mean age 35.8 years (range, 22-65 years). Four had femoral fractures and eleven with tibial fractures. All were due to high-energy trauma and were open ones. Fractures categorized according to $\mathrm{AO}$ classification with 5 type (A), 4 type (B) and 6 type (C) and according to Gustilo-Anderson classification 3 grade (I), 8 grade (II) and 4 grade (III) [9]. All cases initially treated by ring external fixators owing to presence of bone loss (4 cases), marked comminution (3 cases) refracture ( 2 cases) while it was used as a primary treatment for open fractures for rest of cases [10]. Treatment continued till cessation of healing progression and development of clinical and radiological signs of non-union. Exclusion criteria involved young adolescent below 18 years, known case of peripheral vascular disease, complex deformities, significant limb-length inequalities and patients treated primarily with a technique other than ring fixator. The demographic distribution of the cases seen in Table 1. Mean primitive surgeries had done per case 2.3 (range one to four operations). It included repeated debridement, revisions or readjustment of fixator and bone grafting. Active infection was presented at time of presentation in five cases and one case showed deep sequesterum.

\section{Patient's evaluation}

Preoperative assessment included history involving medical co-morbidities, social habits (smoking and alcohol consumption), previous treatment offered for the fracture, complications, time of referral and occupation. Evaluation for signs of infection involved complete blood cell count (CBC), Erythrocyte sedimentation rate (ESR), C-reactive protein (CRP) and Culture and sensitivity for all the

*Corresponding author: Mohamed Aly Abdel-AAl, Consultant Orthopedic Surgery, Elbakry, General Hospital, Ministry of Health, Cairo, Egypt, Tel: +01020995024 E-mail: Eldamaranyg@gmail.com

Received August 17, 2016; Accepted October 12, 2016; Published October 14 2016

Citation: Kornah BA, Safwat HM, Sultan AM, Abdel-AAI MA (2016) Staged Procedures after Failing Ring Fixators of Lower Limb? Series of 15 Cases Abstract. J Trauma Treat 5: 337. doi: 10.4172/2167-1222.1000337

Copyright: (c) 2016 Kornah BA, et al. This is an open-access article distributed under the terms of the Creative Commons Attribution License, which permits unrestricted use, distribution, and reproduction in any medium, provided the original author and source are credited. 


\begin{tabular}{|c|c|c|c|c|c|c|c|c|c|}
\hline Case & Gender & Age & Bone Affected & AO & 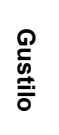 & 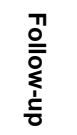 & Time delay & Implant & K-score \\
\hline 1 & $\hat{0}$ & $23 y$ & Tibia & $41 \mathrm{~A} 2$ & II & $26 \mathrm{M}$ & 12 & LPTP & Good \\
\hline 2 & 우 & $28 y$ & Tibia & $43 C 2$ & 1 & $23 \mathrm{M}$ & 16 & LDTP & Excellent \\
\hline 3 & $\delta$ & $64 y$ & Femur & $33 \mathrm{C} 2$ & II & $39 \mathrm{M}$ & 18 & LBDCP & Excellent \\
\hline 4 & $\hat{0}$ & $50 y$ & Tibia & $41 \mathrm{C} 2$ & IIIA & $26 \mathrm{M}$ & 15 & LPTP & Good \\
\hline 5 & 우 & $45 y$ & Tibia & $42 \mathrm{C} 3$ & II & $39 \mathrm{M}$ & 18 & LNDCP & Excellent \\
\hline 6 & $\hat{\sigma}$ & $25 y$ & Tibia & $43 \mathrm{~A} 2$ & I & $29 \mathrm{M}$ & 14 & LDTP & Accepted \\
\hline 7 & 우 & $36 y$ & Tibia & 42B2 & IIIB & $37 \mathrm{M}$ & 16 & LNDCP & Excellent \\
\hline 8 & q & $31 y$ & Femur & $32 \mathrm{~A} 1$ & II & $29 \mathrm{M}$ & 15 & ILFN & Excellent \\
\hline 9 & $\hat{o}$ & $24 y$ & Tibia & $41 \mathrm{~A} 3$ & II & $44 \mathrm{M}$ & 15 & LPTP & Good \\
\hline 10 & $\delta$ & $23 y$ & Femur & $32 \mathrm{~A} 1$ & II & $52 \mathrm{M}$ & 21 & ILFN & Excellent \\
\hline 11 & 우 & $30 y$ & Tibia & $43 \mathrm{C} 2$ & IIIB & $35 \mathrm{M}$ & 13 & LDTP & Poor \\
\hline 12 & $\hat{o}$ & $37 y$ & Tibia & $41 \mathrm{C} 2$ & 1 & $28 \mathrm{M}$ & 12 & LPTP & Good \\
\hline 13 & $\delta$ & $45 y$ & Tibia & 43B1 & II & $33 \mathrm{M}$ & 16 & LDTP & Excellent \\
\hline 14 & $\hat{0}$ & $30 y$ & Femur & 32B2 & II & $46 \mathrm{M}$ & 13 & ILFN & Accepted \\
\hline 15 & 우 & $46 y$ & Tibia & 43B2 & II & $38 \mathrm{M}$ & 17 & LDTP & Good \\
\hline
\end{tabular}

LPTP=Locked proximal tibial plate, $\mathrm{AO}=\mathrm{AO}$ classification, LDTP=Locked distal tibial plate, Gustilo=Gustilo Anderson classification, LBDCP=Locked broad dynamic compression plate, LNDCP=Locked narrow dynamic compression plate, ILFN=Interlocking femoral nail, K score=Karlstrom Olerud Score.

Table 1: Patients demographic data.

cases. Also, patient's nutritional status assessed via total lymphocytic count and Rainey-MacDonald nutritionary index.

Imaging studies done including anteroposterior, lateral and oblique views to assess: fracture deformity and its plane, degree of bone gapping, evaluation of medullary cavity and presence of sequsterm or signs of infection. Surgery planning included the use of an overlay technique using radiographs of the uninvolved side to determine the ideal bony alignment, length, size and contour of the implant to be used. Ethical clearance was obtained from the institutional ethics committee and informed consent forms from all patients were received.

\section{Surgical procedure}

The external fixators removed and pin tracks debrided. For infected cases; cleaning the skin done and site of pseudoarthrosis identified and all soft tissue's interposition removed with sequestrectomy and debridement of all necrotic tissues. Swabs obtained from multiple sites for cultures and sensitivity. Surgical wound wash is performed with gush of saline with antiseptic (Betadine solution) and antibiotic for removing clots and devitalized tissues. Wound closure performed in 9 cases, leaving an aspiration drain which removed within 24 to 48 hours after surgery. Two cases required secondary skin graft for wound closure. The limb stabilized via traction (2 cases), plaster of Paris cast (5 cases), removable aluminium splint ( 3 cases) and functional braces (5 cases). Mono therapy broad spectrum antibiotics started (3rd generation cephalosporin) until the results of the swabs. Patients sent home with regular visits and monitored weekly until the total leukocyte count, C-reactive protein level, and erythrocyte sedimentation rate were within normal limits.

By the second stage; after all clinical, radiological and laboratory signs of infections eventually resolved, patient was readmitted. At surgery; bone grafts were harvested first from iliac crest (13 cases) and in 2 cases additional fibular graft utilized). Site of non-union re-exposed with limitation to the portion of bone on which the plate would lie. Excessive release of the soft tissues attached to bone fragments avoided to preserve their blood supply. Trimming and shingling of bony ends done (together with opening of medullary canal) to get maximum bone contact and achieving an inherently stable fracture. In some cases, an AO/ASIF femoral distractor applied and used to correct the length and alignment of bone without marked soft tissue stripping and devitalisation. Internal fixation undertaken. Choice of the fixation depended upon: level of non-union, presence of an open medulla and discretion of the individual surgeons. Locked plates (owing to presence of osteoporosis) used in 12 patients (locked broad dynamic compression plate in one case, locked narrow compression plate in 2 cases, locked distal tibial plate in 5 cases, locked proximal tibial plate in 4 cases while Interlocking femoral nail was used in 3 cases. Length of plate was chosen so that at least three screws placed both proximally and distally (for tibial fractures) and 4 screws proximal and distal for femoral ones. More screws used when underlying bone was seen to be severely osteoporotic. Following stable fixation, autogenous bone grafts applied around the non-union to fill the gap if present and to accelerate bone healing. Wound then closed over a suction drain. All patients were operated upon by the authors with the same technique. The operative procedure is described in Figure 1.

\section{Postoperative management}

Patients were allowed for toe touch bearing on first post-operative day and kept non-weight-bearing for 3 weeks. Progressive increase in weight-bearing was encouraged. Full weight bearing allowed when radiological bone healing signs appear and this ranged (2 to 5.5 months) with mean 4.2 months. A program of rehabilitation protocol started from second day postoperative with isometric and active assisted exercises (after drains removal) of all joints to alleviate Knee and Ankle joints stiffness developed during period of the fixators. Intravenous antibiotics were given for one week, followed by oral antibiotic for more 2 weeks (Table 1 ).

Patients reviewed clinically at regular intervals of 2 weeks, 6 weeks, 3 months, 6 months and one year with serial radiographs. The functional results evaluated using trauma outcomes measure (TOM) proposed by AO foundation [11] which show the state of progression or regression of the functional outcomes during follow-up period (Table 2). Every patient was asked to answer the questionnaire after being translated into Arabic language and ensuring that the patient perceived and understand it fully. Patients with a score less than 27 recorded as having fair or poor function (unsatisfactory outcome). Those with 27 points or 
Citation: Kornah BA, Safwat HM, Sultan AM, Abdel-AAI MA (2016) Staged Procedures after Failing Ring Fixators of Lower Limb? Series of 15 Cases Abstract. J Trauma Treat 5: 337. doi: 10.4172/2167-1222.1000337

Page 3 of 7

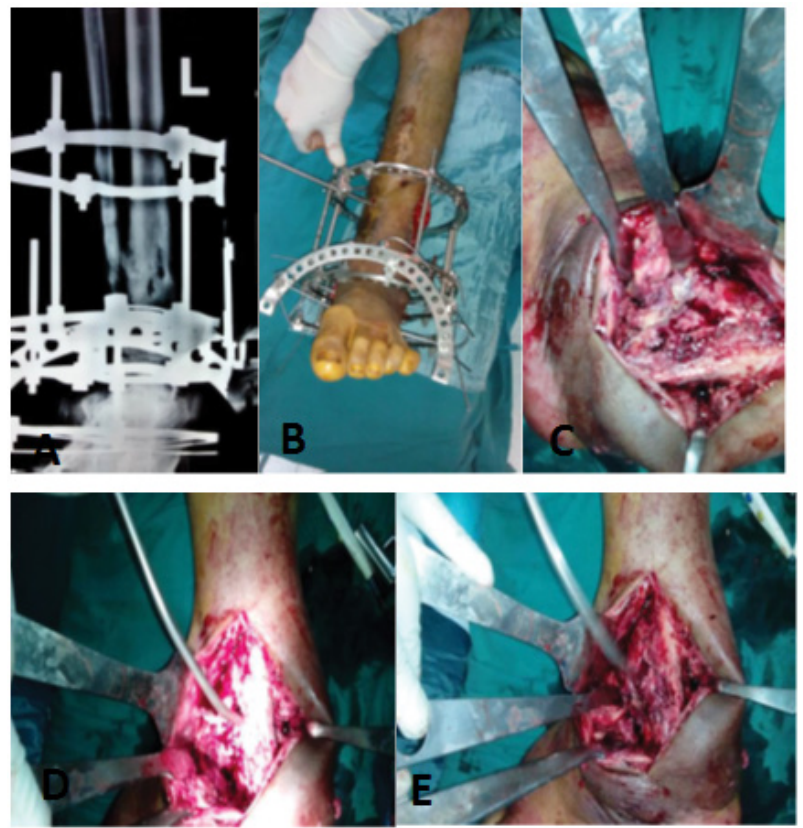

Figure 1: Operative details of non-united lower 3rd tibia.

A) Fracture nonunion in Ilizarove fixator B) Photo of the frame C) Intraoperative showing site of nonunion D) \& E) Debridement of bone and pin track

\begin{tabular}{|c|c|c|c|c|}
\hline \multicolumn{3}{|c|}{ Follow up } \\
\hline Outcomes & Number of patients & 3 months & $\mathbf{6}$ months \\
\hline TOM & 15 & $26.3(25.4-27.3)$ & $30.4(29.4-32.1)$ \\
\hline TOM: Trauma Outcomes & & & $33.6(32.6-40)$ \\
\hline
\end{tabular}

Table 2: Mean patient-reported scores for the TOM.

\begin{tabular}{|c|c|c|c|c|}
\hline S. No & Measures & 3 points & 2 points & 1 point \\
\hline 1 & Pain & No & Little & Severe \\
\hline 2 & Difficulty in walking & No & Moderate & Severe limp \\
\hline 3 & Difficulty in stairs & No & Supported & Unable \\
\hline 4 & Difficulty in previous sports & No & Some sports & Unable \\
\hline 5 & Limitation at work & No & Moderate & Unable \\
\hline 6 & Status of skin & Normal & various colors & Ulcer/fistula \\
\hline 7 & Deformity & No & Little, up to $7^{\circ}$ & Remarkable, $>7^{\circ}$ \\
\hline 8 & Muscle atropy & $<1 \mathrm{~cm}$ & $1 \mathrm{~cm}$ to $2 \mathrm{~cm}$ & $>2 \mathrm{~cm}$ \\
\hline 9 & Shortening & $<1 \mathrm{~cm}$ & $1 \mathrm{~cm}$ to $2 \mathrm{~cm}$ & $>2 \mathrm{~cm}$ \\
\hline 10 & Loss of motion at knee joint & $<10^{\circ}$ & $10^{\circ}$ to $20^{\circ}$ & $>20^{\circ}$ \\
\hline 11 & Loss of subtalar motion & $<10^{\circ}$ & $10^{\circ}$ to $20^{\circ}$ & $>20^{\circ}$ \\
\hline
\end{tabular}

Table 3: Characteristics of modified Karlstrom-Olerud score.

\begin{tabular}{|l|l|}
\hline & \multicolumn{2}{|c|}{ Karlstrom-Olerud score } \\
\hline Excellent & 33 points \\
\hline Good & $32-30$ points \\
\hline Satisfactory & $29-27$ points \\
\hline Moderate & $26-24$ points \\
\hline Poor & $23-21$ points \\
\hline
\end{tabular}

Table 4: Karlstrom-Olerud score.

\begin{tabular}{|c|c|}
\hline Clinical results & No. of patients \\
\hline Excellent & 7 \\
\hline Good & 5 \\
\hline Satisfactory & 2 \\
\hline Moderate & - \\
\hline Poor & 1 \\
\hline
\end{tabular}

Table 5: Distribution of cases according to modified functional evaluation of Karlstrom-Olerud score. 


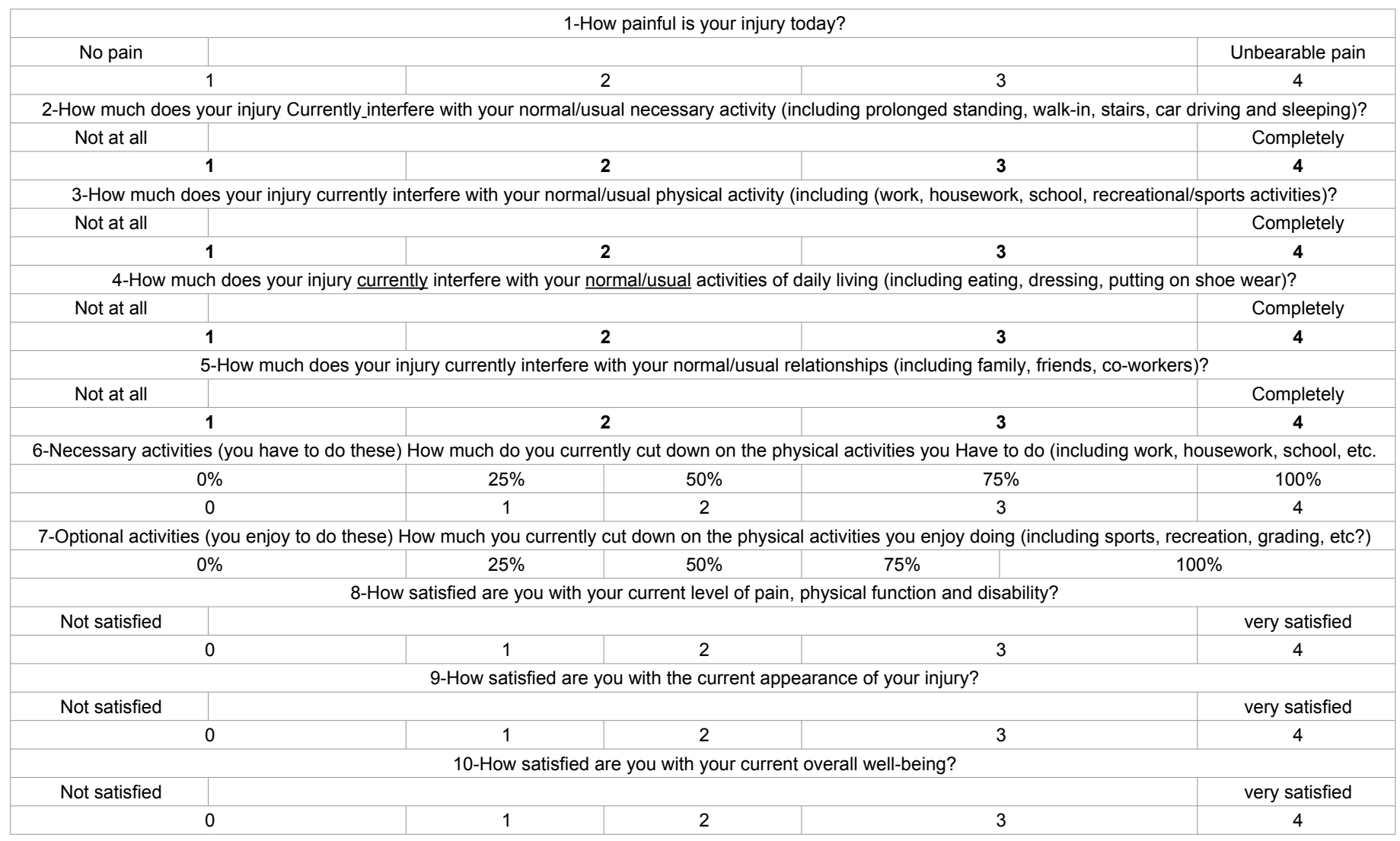

Table 6: Trauma outcomes measure (TOM) questionnaire.

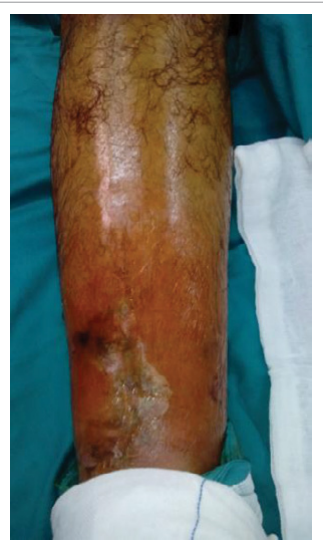

Figure 2: Deep infection with sequestrum.

more considered good or excellent function (satisfactory outcome). At final follow-up situation, the capacity to bear weight without pain, any leg-length discrepancy, alignment and range of movement of hip, knee and ankle were evaluated. Radiographic evaluation included: bone union, malunion, axis deviation, limb shortening and any evidence of implant failure. The final functional outcome was evaluated according to modified functional evaluation score of Karlstrom-Olerud (Tables 3-6) [10].

\section{Results}

Mean follow-up was 35 months (range 24 to 52 months). Average duration of non-union was 9.8 months (range 8 to 13 months). Average delay prior to osteosynthesis (until no signs of infection) 3 weeks (range 2 to 4 weeks). The time varied depending upon condition of pin-tracts, timing of infection eradication and general condition of patient. Fourteen cases get full union on an average 5.2 months (range 4 to 8 months) and one case exhibited persistent non-union which had been overcome by re-grafting and bone marrow injection (BMI). Union was assessed both clinical and radiological. All united cases were able to bear full weight without pain at the latest follow-up. No angular deformity of $>10^{\circ}$ in any plane detected. Leg-length discrepancy detected in 3 cases (20\%), with an average shortening $<3 \mathrm{~cm}$.

All patients had full range of motions at the hip and ankle joints. Eleven (73.3) regained full movement at the knee (compared with sound side) while 4 patients $(26.7 \%)$ had residual limitation of knee flexion varied from $15^{\circ}$ to $30^{\circ}$. Superficial infection occurred in 3 cases $(20 \%)$, and one case showed late infection with formation of sequesterum in distal tibia and was operated upon and all responded well to antibiotic therapy (Figure 2). No patient had neither residual knee instability nor implant failure. Overall complications included: one case of nonunion, 3 cases of superficial infection (involving skin edges), one deep infection (infection extended to muscles and fascia), 4 cases knee stiffness and 3 cases limb length discrepancy (LLD) (Figures 3-5 are cases presentation.

\section{Discussion}

Implant failures normally range from $0.35 \%$ to $0.44 \%$ of osteosynthesis [5]. In our study, this rate was very high (17.58\%). Even when we consider only patients initially operated in our service, the rate is $10 \%$ which is still very high. This because of poor control of known factors: surgeon failure, implant failure, patient and physiotherapy related failures [1-3]. This rate is not far from the $10 \%$ to $16 \%$ found by Moyikoua et al. working almost in similar conditions [6]. 

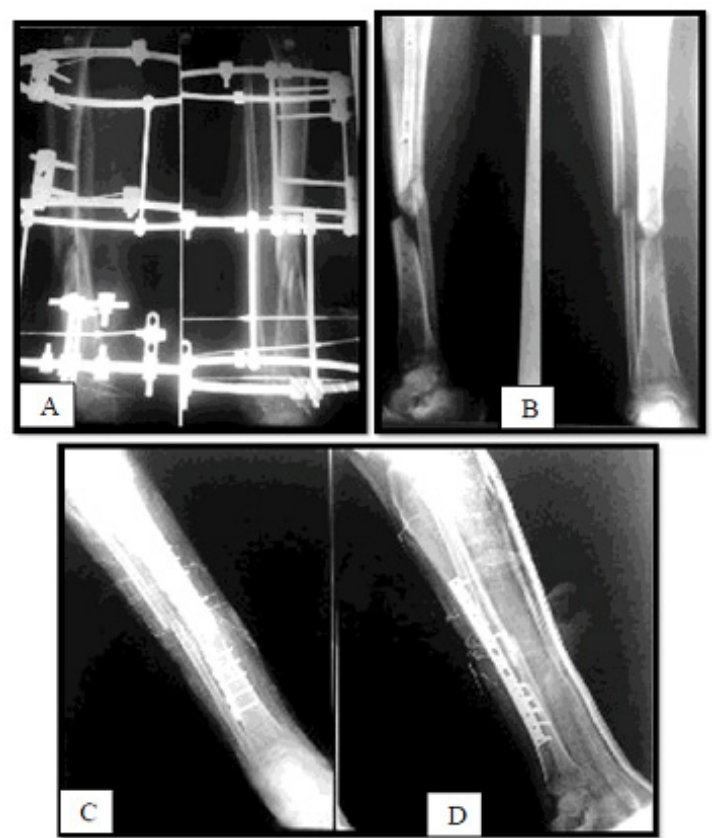

Figure 3: A) Adult patient treated by ring fixator with no evidence of union after 10 months, B) $X$ ray show non-union of the fracture and removal of fixator, C) and $D$ ) Post-operative $X$ ray shows plate fixation and bone grafting.
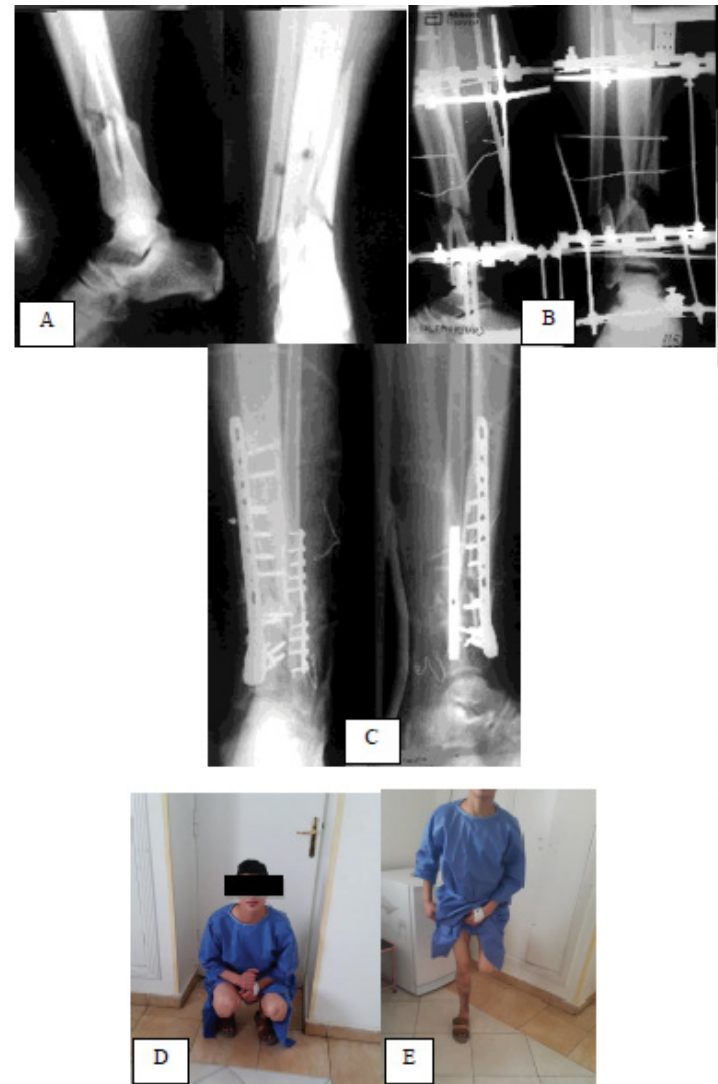

Figure 4: A) 27 years old male involved in road traffic accident treated initially by ring fixators B) X-ray show ring fixators after 10 months with nonunion C) Internal fixation with distal tibial locked plate and bone grafting D) Excellent functional outcome (full knee flexion), E) Full weight bearing on the affected limb.
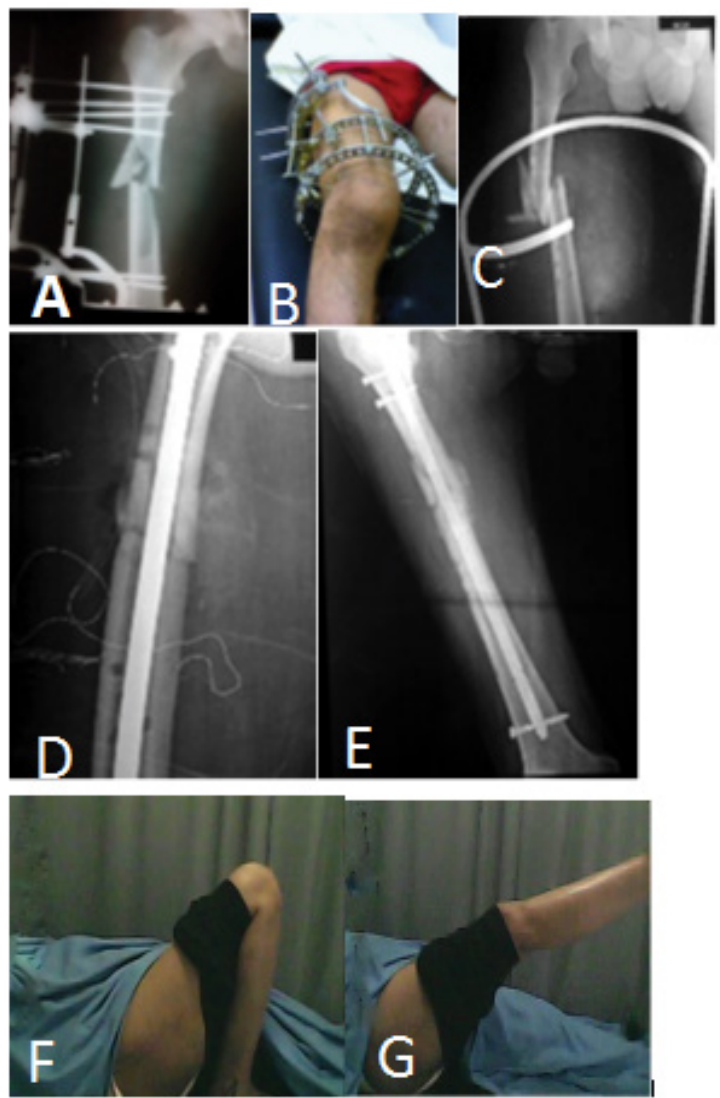

Figure 5: A) and B) Adult male with open comminuted shaft femur treated with ring fixator, C) $\mathrm{X}$ ray of non-union (after Fixator removal) in splint during waiting until signs of infection resolve, D) Immediate post-operative X-ray after fixation of the fractures by intramedullary interlocking nail and bone grafting, E) 2 months post-operative $x$ ray with healing of the fracture, $F$ ) and $\mathbf{G}$ ) good range of motion of hip and knee joints.

Ring external fixation is a valuable tool for myriad of applications including congenital and posttraumatic limb reconstruction, complex arthrodesis, management of osteomyelitis, bone defects, deformity correction and treating acute fractures particularly the open ones [11]. In circular external fixators, less damage done by thin $\mathrm{K}$-wires of Ilizarove, however it is accompanied by risk of developing pin tract infection. Furthermore, K-wires placed across muscle tissues and retained for a long time would affect motion of neighboring joints. Failure of fractures to unite after treatment with ring external fixation is a challenge for orthopaedic surgeons, especially in the presence of osteoporosis, joint stiffness persistent complications in addition to dissatisfaction of the patient. Non-union may be attributed to: bone defect, persistent pin track infection, lack of mechanical support, deficiency of biological environment necessary for bone healing and lack of experienced surgeon [12]. The quality of soft-tissue envelope, blood supply around the fracture, mechanical stability at the fracture site are important factors for deciding the treatment modality [13]. The goal of surgery in our study is achieving sound union, early mobilization of patient and prohibiting complications. It is not simply changing ring fixators to internal fixation modality during the course of treatment of open fractures but osteosynthesis utilized after complete failure of ring fixators to achieve bone union. The problem of non-union after external fixation application is the presence of pin tracks which make the fractures potentially infected $[13,14]$. We planned to achieve our target (healing of non-union) through 2 stages. 
First to convert infected non-union into non-infected one via complete eradication of infection and assure that through laboratory infection profile [15]. CRP is the most accurate indicator of infection, but it is not necessarily specific and cultures may be helpful though findings are often negative, especially in patient on antibiotic therapy [16]. Also, patient nutritionally assessed using both nutritional index of RaineyMacDonald and total lymphocyte count. These two parameters can identify those patients who are susceptible to develop postoperative complications mainly infection [17].

Many studies had focused specifically on non-union after failure of ring external fixation. Literatures showed that achieving union of non-united fracture developed during the course of treatment of open fractures treated with external fixators is a great challenge when both intrinsic and extrinsic blood supply had been damaged by infection or multiple operations [18].

We utilize Locked compression plates (owing to localized osteoporosis) which summit the characteristics of biological fixation with capability to preserve residual blood supply that already halted by previous surgeries.

Comparing the results with other studies utilize the same technique; Van den Bossche et al. reported on 57 patients mean union time of 40.6 weeks [19]. It is considerably long time compared to current study (5.2 months). This may be attributed to situation that most of our cases are grade (I) and grade II open fractures (11 cases)., which have apparently small and clean looking skin wounds. Also proper debridement prevents development of infection in addition to preserving bone fragments with soft tissue attachment which avoid the occurrence of gapping and the use of bone grafting in all cases. Also there were no cases of deep infection and one case of malunion. Functional outcome was good to excellent in all their cases. In our study non-union rate $6.7 \%$ which is relatively lower than many series, Wheelwright et al. [20] showed that if secondary nailing is delayed until after granulation of the pin sites the technique would be associated with a low infection rate. They reported union rate $11.6 \%$ and $7 \%$ infection rat. Bernat et al. [21] reported results of 17 patients with $100 \%$ union, no deep infection but only 2 superficial ones. Monni et al. [22] on dealing with 5 limbs for delayed conversion of fixators to internal fixation; they reported $13.3 \%$. infection though all their cases achieve full union.

The incidence of complications in the series is relatively low including: knee stiffness (26.7\%), superficial infection (20\%), deep infection (6.7\%) and limb length discrepancy (20\%). No cases of implant failure because bone graft used in all cases overcomes any bone defect and minimize exposure of the plate to concentrated bending or torsional forces. Consequently, this plate is not subjected to cyclic loading that predisposes to implant failure [23].

The functional outcomes do not rely on bone union (and capability of weight bearing) as sole parameter for evaluation. Other prerequisites may affect the situation as: general condition of the patient, pain tolerance, muscle status, physical activities and psychological status of the patient which is markedly affected by prolonged presence of the fixator with its remedies on patient's daily personal, social and familial activities. All outcome measures in our study improved over time between 3-months and 1-year. The one-year mean TOM score is less prone to a ceiling effect (i.e. reaching the upper-most end on the scale) "activities of daily living" dimension. In fact, the average 1-year TOM score only lay at $20 \%$ below the upper limit to the scale, while $30 \%$ of the patients reached the maximum score of 40 on the TOM scale at 1-year follow up (Table 2).
According to Modified functional outcome score of KarlstromOleruds, the final functional results were: excellent in 7 cases (46.7\%), good in 5 cases (33.3\%), accepted in 2 cases (13.3) and poor in one case $(6.7 \%)$ and these results are fairly reasonable.

\section{Conclusion}

Two-stage treatment protocol of non-unions of long bone after ring fixation is an effective tool to achieve bony union. For optimization of the functional results; infection must be eradicated well and this should be guaranteed by laboratory investigations.

The main limitations of our study are: small number of cases, the need for control group to compare the results with other single stage protocol. Also; being some cases had infected non-union while other had no infected non-union may have some impact on final outcome

Compliance with ethical standards

- No benefits in any form have been received or will be received from a commercial party related directly or indirectly to the subject of this article.

- Ethical approval: This article does not contain any studies with animals.

- Informed consent was obtained from all individual participants included in the study according to the rules of the hospital research ethical committee.

All procedures performed in our study were in accordance with the ethical standards of the institutional research committee and with the 1964 Helsinki declaration and its later amendments or comparable ethical standards.

\section{References}

1. Fragomen AT, Rozbruch SR (2007) The mechanics of external fixation. HSS J 3: 13-29.

2. Einhorn TA (1995) Enhancement of fracture-healing: in current concepts review. J Bone Joint Surg 77: 940-956.

3. Papaioannou N, Mastrokalos D, Papagelopoulos PJ, Tyllianakis M Athanassopoulos $M(2001)$ Nonunion after primary treatment of tibia fractures with external fixation, Eur J Orthop Surg Traumatol 11: 231-235.

4. Stojković B, Milenković S, Stanojković m, Radenković M, Stanojković M, et al. (2006) Tibial shaft fractures treated by the external fixation method. Med Biol 13: $145-147$

5. Weber BG, Cech O (2009) Pseudoarthrosis; Pathology, Biomechanics Therapy, Results. Berne, Switzerland: Hans Huber Medical Publisher; (1976). Strategies Trauma Limb Reconstr. 4: 81-87.

6. Apard T, Bigorre N, Cronier P, Duteille F, Bizot P (2010) Two-stage reconstruction of post-traumatic segmental tibia bone loss with nailing. Orthop Traumatol Surg Res 96: 549-553.

7. Galfat DR, Agnihotri A, Bansal A (2013) Management of infected non-union of long bones with antibiotic impregnated cement nail. NJMDR 1: 25-32.

8. Bansal M, Gupta P (2015) Two stage procedures for treatment of infected non union using antibiotics cement impregnated intramedullary nail (ACIIN) International Journal of Orthopaedics Traumatology \& Surgical Sciences 1: 6-12.

9. Müller ME, Nazarian S, Koch P, Schatzker J (1990) The comprehensive classification of fractures of long bones. New York: Springer-Verlag.

10. Gustilo RB, Anderson JT (1976) Prevention of infection in the treatment of one thousand and twenty-five open fractures of long bones: retrospective and prospective analysis. J Bone Joint Surg Am 58: 453-458.

11. Suk M, Hanson BP, Norvell DC, Helfet DL (2004) "Musculoskeletal outcomes measures and instruments" in AO Handbook, pp. 1-444, Georg Thieme Stuttgart, Germany, (1stedition). 
Citation: Kornah BA, Safwat HM, Sultan AM, Abdel-AAI MA (2016) Staged Procedures after Failing Ring Fixators of Lower Limb? Series of 15 Cases Abstract. J Trauma Treat 5: 337. doi: 10.4172/2167-1222.1000337

Page 7 of 7

12. Kalstrom G, Olerud S (1974) Fractures of the tibial shaft, A critical evaluation of treatment alternatives. Clin Orthop Relat Res 1: 82-115.

13. Emara KM, Allam MF (2008) Ilizarov external fixation and then nailing in management of infected nonunions of the tibial shaft. J Trauma 65: 685-691.

14. Beltsios M, Savidou O, Alexandropoulos P, Papagelopoulos P (2009) External fixation as a primary and definitive treatment for tibial diaphyseal fractures. Strategies Trauma Limb Reconstr 4: 81-87.

15. Chan YL, Liao HC, Tsay PK, Chang SS, Chen JC, et al. (2002) C-reactive protein as an indicator of bacterial infection of adult patients in the emergency department. Chang Gung Med J 25: 437-445.

16. Päkönen M, Kallio MJ, Kallio PE, Peltola H (2010) Sensitivity of erythrocyte sedimentation rate and $\mathrm{C}$-reactive protein in childhood bone and joint infections. Clin Orthop Relat Res 468: 861-866.

17. Puskarich CL, Nelson CL, Nusbickel FR (1990) The use of two nutritional indicators in identifying long bone fracture patients who do and do not develop infections. J Orthop Res 8: 799-803.
18. Ma CH, Yu SW, Tu YK, Yen CY, Yeh JJ, et al. (2010) Staged external and internal locked plating for open distal tibial fractures: A retrospective study of 16 patients. Acta Orthop 81: 382-386.

19. Van den Bossche MR, Broos PL, Rommens PM (1995) Open fractures of the femoral shaft treated with osteosynthesis or temporary external fixation. Injury 26: 323-325.

20. Wheelwright EF, Court-Brown CM (1992) Primary external fixation and secondary intramedullary nailing in treatment of tibial fractures. Injury 23:373-376.

21. Bernat M, Lecoq C, Lempidakis M, Martin G, Aswad R, et al. (1996) Secondary internal osteosynthesis after external fixation for recent or old open fracture of the lower limb. Rev Chir Orthop Reparatrice Appar Mot 82: 137-144.

22. Monni T, Birkhlotz FF, Lang P, Snyckers CH (2013) Conversion of external fixation to internal fixation in a non-acute, reconstructive setting: a case series. Strategies Trauma Limb Reconstr 8: 25-30.

23. Egol KA, Kubiak EN, Fulkerson E, Kummer FJ, Koval KJ (2004) Biomechanics of locked plates and screws. J Orthop Trauma 18:488-493. 